\title{
Psychosocial Adaptation to Stoma Surgery: A Review
}

\author{
M. J. T. M. Bekkers, ${ }^{1,6}$ F. C. E. van Knippenberg, ${ }^{2}$ \\ H. W. van den Borne, ${ }^{3}$ H. Poen, ${ }^{4}$ J. Bergsma, ${ }^{5}$ and \\ G. P. vanBergeHenegouwen
}

Accepted for publication: May 2, 1994

During the last decade strong improvements have been made in the medical care of patients with a digestive tract stoma, particularly with regard to nursing skills and to the quality of collecting material for faecal products. Scientific investigation into the psychosocial adjustment of patients after stoma surgery has intensified as well, giving us indications for quality of life. These developments induced a review of the actual state of affairs in psychological issues. After evaluating the results of psychosocial stoma research, it can be concluded that the technical improvements in stoma care during the past decade did not result in a decline in psychosocial problems after stoma surgery. However, there are some serious problems when interpreting the results of studies in this field of investigation. Stoma surgery is not per se solely responsible for the reported psychosocial problems, first, because many conclusions are based on research studies with poor design and, second, because these studies lack a theoretical framework within which the process of psychosocial adjustment has been measured and explained. This review assesses the most current developments and controversies in this field.

KEY WORDS: stoma surgery; stoma care; psychosocial adjustment; quality of life.

This study was made possible by the financial support of Glaxo Nederlands, B.V., and Convatec-Squibb, B.V., The Netherlands.

${ }^{1}$ The Netherlands Institute of Primary Health Care (NIVEL), P.O. Box 1568, 3500 BN Utrecht, The Netherlands.

${ }^{2}$ CPWO Institute, Klundert, The Netherlands.

${ }^{3}$ Department of Health Education, State University Maastricht, Maastricht, The Netherlands.

${ }^{4}$ Department of Gastroenterology, University Hospital Utrecht, Utrecht, The Netherlands.

${ }^{5}$ Department of Medical Humanities, Loyola University Chicago, Chicago, Illinois.

${ }^{6}$ To whom correspondence should be addressed. 


\section{INTRODUCTION}

Stoma stems from the Greek word "stoma," literally meaning "mouth." Medically, the word is used to indicate "an artificial opening in the digestive tract, connected with the skin' (Eyskens et al., 1991, p. 245). Depending on the location of the stoma in the digestive tract, a differentiation can be made between a colostomy (a stoma on the large intestine) and an ileostomy (stoma on the small intestine). Often these stomata serve as an artificial anus in order to evacuate contents of the bowel. Apart from digestive tract stomas, also stomas with an urologic indication can be applied. In this paper only problems of digestive tract stomas will be discussed. The two most frequently mentioned indications for colostomy or ileostomy are colon cancer and chronic enteritis. In the case of an eradicate colon or colorectal cancer, a colostomy is constructed from the healthy part of the large intestine. In surgical treatment of inflammatory bowel diseases of the colon, i.e., Crohn's disease and chronic colitis (see Glossary), an ileostomy is constructed after complete resection of the diseased colon (see Glossary). The stoma itself can be temporary or permanent: this depends on both the location and the type of disease. The number of stoma patients in the United States has been estimated as 1.5 million by the American United Ostomy Association, with an incidence of about 100,000 patients per year (United Ostomy Association, 1988). Since the midseventies, stoma care has improved with the development of better, innovative and alternative surgery techniques. The expansion of the group of skilled stoma nurses and the introduction of highquality stoma appliances have also contributed a great deal to the quality of stoma care. During these developments the need for more insight into psychosocial problems of stoma patients and the need to offer more support became evident. Stoma surgery is a radical treatment with permanent physical damage disfigurement, loss of an important bodily function, and a change in personal hygiene. These physical consequences have serious implications for emotional welfare, social relations, and activities. Scientific research may help to clarify the main problems of coping and adjustment.

\section{PSYCHOSOCIAL RESEARCH}

\section{Review}

Although stoma surgery has been applied routinely for several decades and the deteriorating effects on quality of life were directly evident, research into the psychosocial consequences is relatively recent. Since the first systematic psychosocial study with stoma patients in 1947 (Dukes, 
1947), the number of studies is steadily growing, with a substantial number of publications between 1980 and 1990 . Figure 1 shows the number of published articles per decade ${ }^{7}$ in the Index Medicus and in the CD-ROM files Medline and PsycLit, per decade.

In 1984 Oades-Souther and Olbrisch published a review of 18 articles, concerned with the prevalence of psychological problems following stoma surgery. Their investigation confirmed the existence of a variety of psychosocial problems, especially in the emotional, sexual, and social area. Results of the studies should be interpreted with caution, due to the methodological limitations. These limitations resulted from the retrospective character of the investigations, biased respondent selection (mainly through patient organizations), and limited attention for the contribution of intraand interpersonal factors in the adaptation process. Furthermore, it should be pointed out that most of the patients in the studies (Oades-Souther and Olbrisch, 1984) were treated before the major improvements in stoma care. In view of the improvements in stoma care, as well as the strong increase

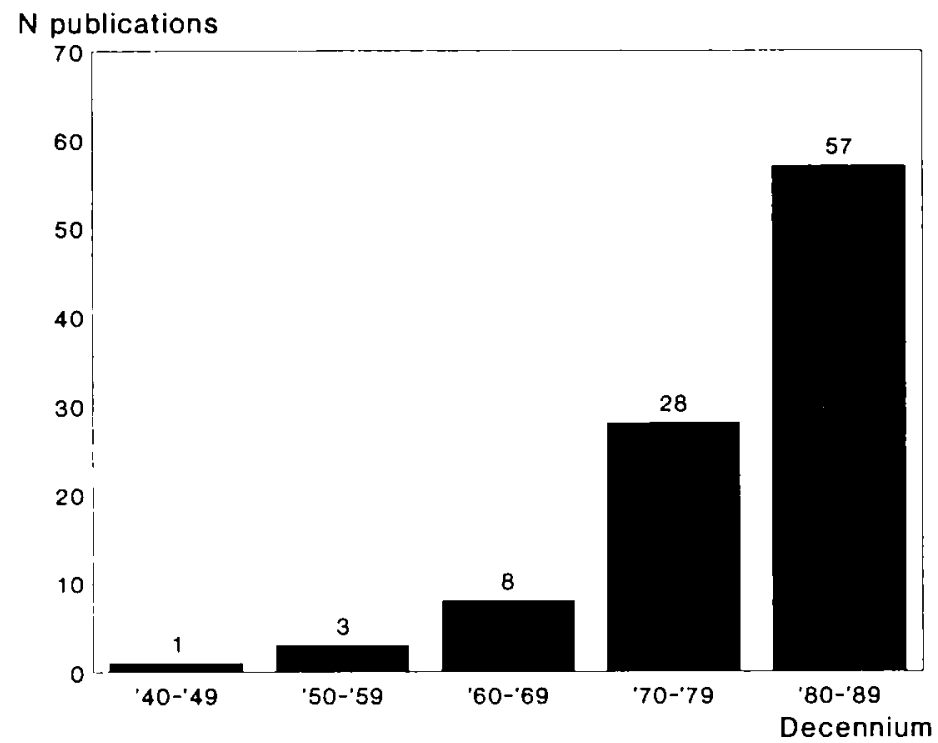

Fig. 1. Number of publications on psychosocial consequences of colostomy/ileostomy surgery, per decade.

${ }^{7} \mathrm{~A}$ complete list of publications is available. 
in the number of studies in this field, it is relevant to provide an actual review of the current situation.

\section{Selection of Literature and Key Questions}

Since the review by Oades-Souther and Olbrisch (1984), 22 articles $^{8}$ have been published, concerning 17 studies into the psychosocial impact of stoma surgery. These studies (published between 1982 and 1991; Tables I-IV) can be divided into four categories based on research design: retrospective studies with and without comparison groups of patients and prospective studies with and without comparison groups of patients. Evaluation of studies were guided by the following questions:

1. What are the clear-cut psychosocial problems after stoma surgery? Are the psychosocial problems mentioned in earlier studies comparable to the problems mentioned in recent studies concerning type and severity? The recent developments in stoma care may possibly have contributed to an improvement in the adaptation process of stoma patients after surgery.

2. Which demographic, medical, and psychological factors cause differences in psychosocial adaptation between patients? No systematic review of factors explaining these differences is available.

3. Can the literature dealing with psychosocial consequences of stoma surgery give indications for a deliberate choice between stoma surgery and alternative surgery procedures? Various reports have compared the psychosocial consequences of stoma surgery with the psychosocial response to other, more recent, alternative surgery techniques, which avoid the necessary of a stoma.

4. What are the methodological drawbacks of recent investigations? Oades-Souther and Olbrisch (1984) already pointed out important methodological shortcomings of some of the earlier studies. To what extent are the critics of Oades-Souther and Olbrisch still valid?

\section{Old vs Recent Psychosocial Problems}

To find an answer to the first question we will take a closer look at the type of psychosocial problems mentioned in studies published before 1982 and the type of problems appearing in more recent studies. Further-

\footnotetext{
${ }^{8}$ Much research has been done into the incidence of functional sexual problems (impotence, painful intercourse). This article reviews mainly publications dealing with perceptional sexual problems (pleasure, interest, motivation).
} 
more, we made a comparison of severity of old and recent psychosocial problems.

There are obvious similarities in the types of psychosocial problems that are reported in studies prior to and after the improvements in the quality of care of stoma patients. Oades-Souther and Olbrisch (1984) classified these problems into six global domains: (1) emotional problems, (2) problems related to social activities, (3) interpersonal relationships, (4) sexuality, (5) (paid) work, and (6) general physical health. This organization can also be applied to the 22 studies published since 1982 .

The studies reported important emotional problems as anxiety and depression (McLeod et al., 1986; Williams and Johnston, 1983; Keltikangas-Järvinen and Järvinen, 1987; Thomas et al., 1984, 1987a; Wade, 1990), a diminished feeling of self-esteem, feelings of inferiority and shame (MacDonald and Anderson, 1984), serious physical impairment (Foulis and Mayberry, 1990; Williams and Johnston, 1983; MacDonald and Anderson, 1984) decreased self-confidence (Gutman and Reiss, 1985; Foulis and Mayberry, 1990), hopelessness (Keltikangas-Järvinen and Järvinen, 1987), and an increased anger and irritation (Follick et al., 1984; Thomas et al., 1984). The stoma has been marked as a restrictional factor of the social life (Gutman and Reiss, 1985; Foulis and Mayberry, 1990; van de Wiel et al., 1991; Thomas et al., 1984, 1987a): Patients appeared to be socially less active and feel restrictions in sports, recreation, travelling, and leisure-time activities. Impaired partner relationship including nonacceptance by the partner (Follick et al., 1984; Macdonald and Anderson, 1984; La Monica et al., 1985) and sexual problems are frequently mentioned. Sexual problems include functional problems, such as impotence, problems with ejaculation, and painful intercourse, as well as emotional problems, such as decrease in pleasure, interest, and motivation (Gutman and Reiss, 1985; van de Wiel, 1991; MacDonald and Anderson, 1985; La Monica et al., 1985). Stoma surgery after resection of the rectum gave rise to considerably more sexual problems than stoma surgery after (sub)total colectomy (see Glossary) due to ulcerative colitis or polyposis coli (see Glossary) (van de Wiel et al., 1991; Hengeveld, 1987). Stoma surgery was also found to have a major impact on paid work and domestic activities, related to physical restrictions, returning to prior work, or getting a new job (Follick et al., 1985; Whates and Irving, 1984; Gutman and Reiss, 1985). Patients need a relatively long period of recovery, before they resume work. Thomas et al. (1987a) and Wijke (1988) found 13 and 35\%, respectively, of patients did not return to their preoperative job within a year after stoma surgery. Most of them, however, return to work eventually: Only about $5 \%$ of these patients definitively stop working (Whates and Irving, 1984; Wyke et al., 1988). The physical health is qualified in recent literature as satisfactory to good. 


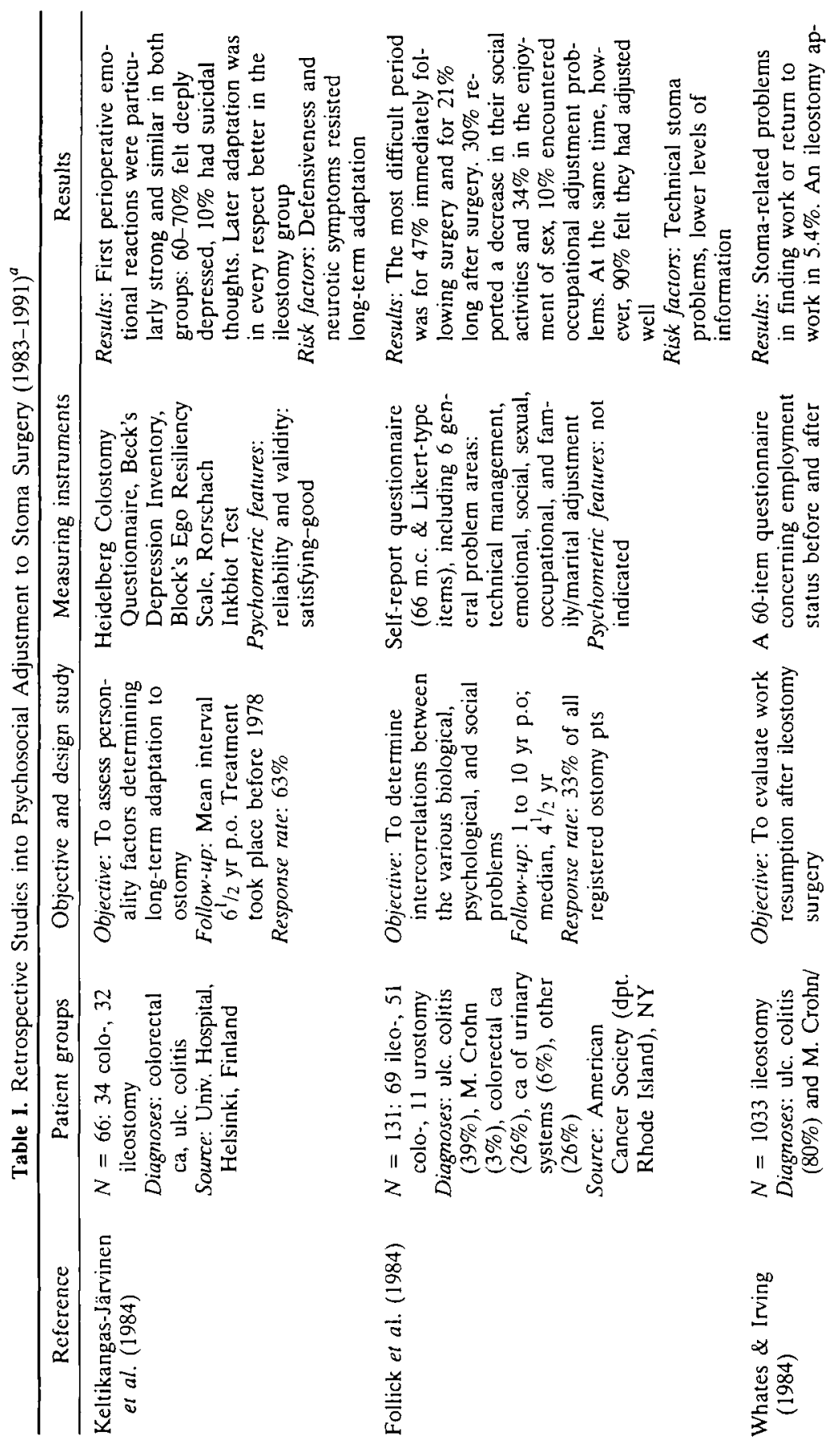


它琉

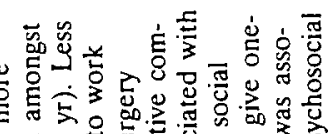

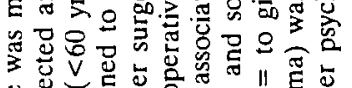

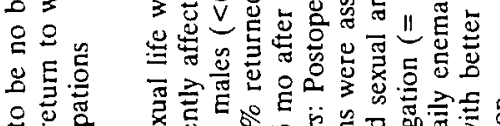

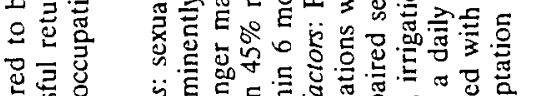

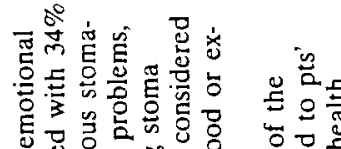

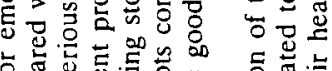

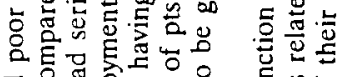

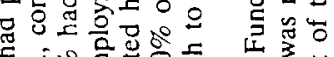

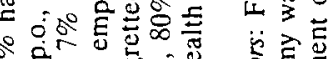

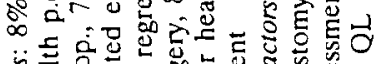

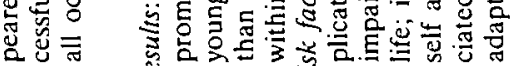

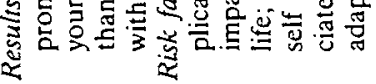

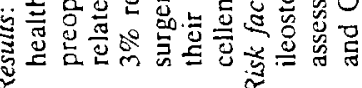

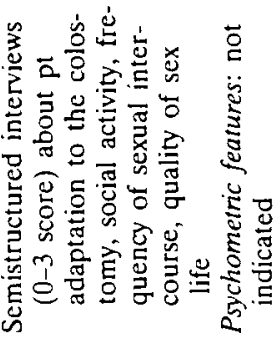

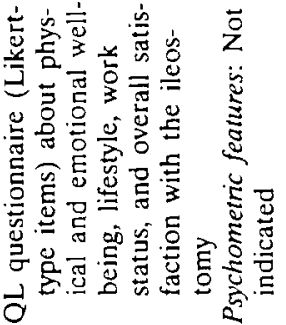

$\dot{0}=\stackrel{\check{\sigma}}{\Omega}$

ᄃ

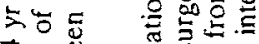

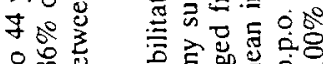

$\circ \infty$ 实

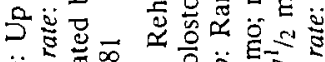

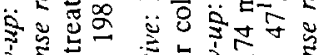

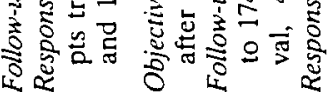

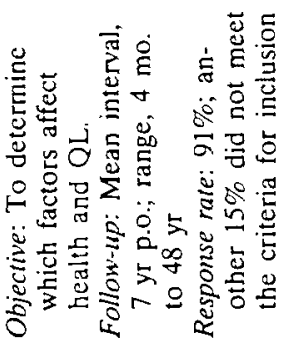

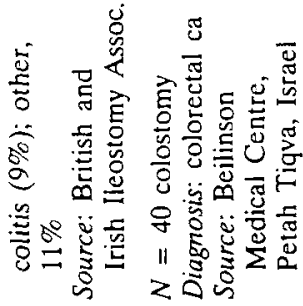

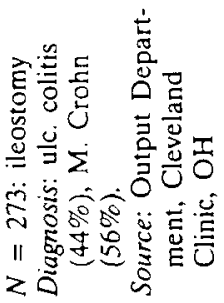

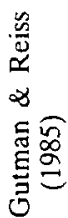

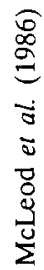




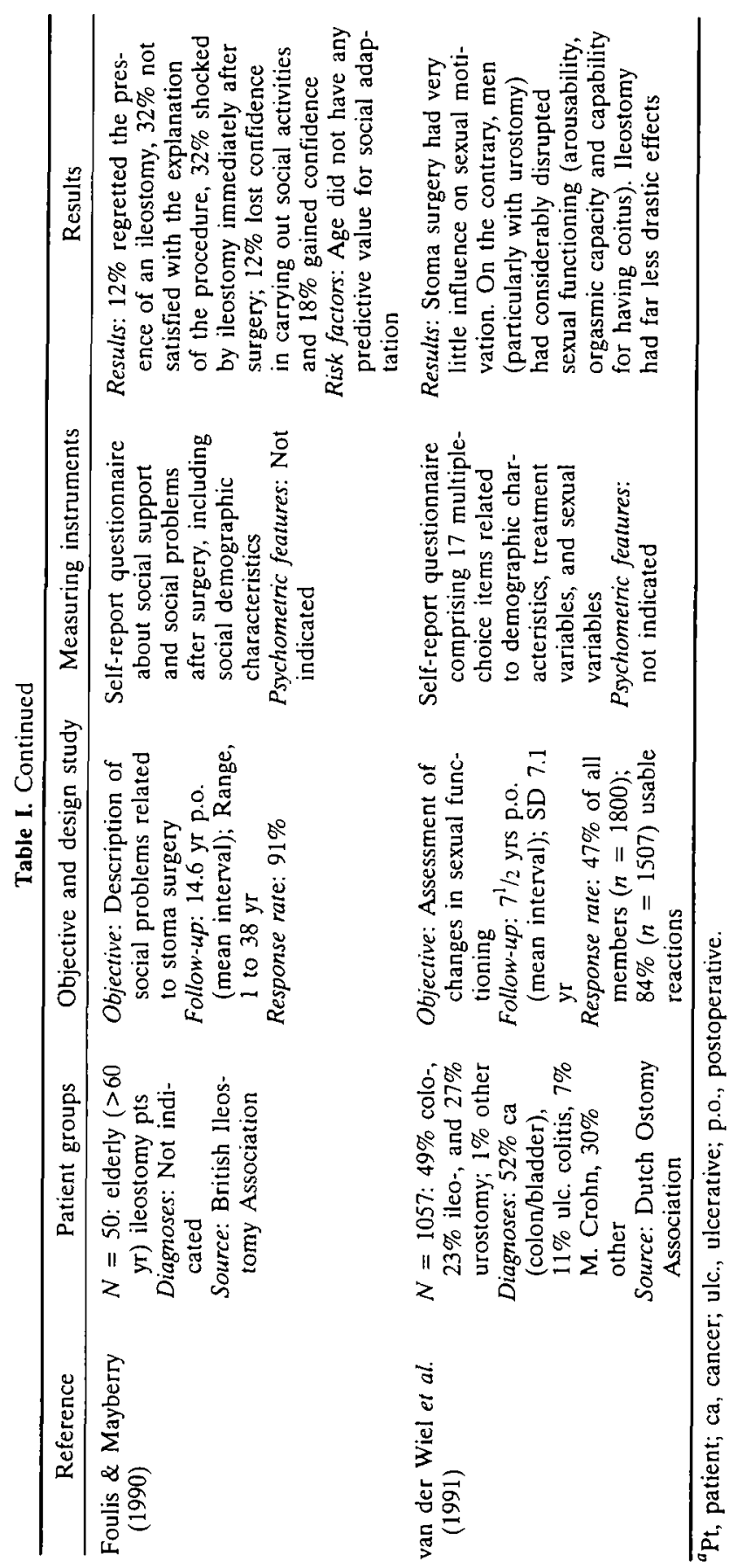


The next step was to make a comparison between the severity of old and that of recent problems. Therefore, we gathered prevalent data concerning each type of psychosocial problem in studies published before and after 1982 (Table V). Per study, the number of patients experiencing serious problems in a domain of psychosocial adaptation was determined. Per problem area, the total number of nonadjusted patients was divided by the total number of patients studied. In this way we calculated a weighted percentage for each of the five kinds of psychosocial problems mentioned.

Table $\mathrm{V}$ shows that prevalence figures concerning depression, diminished social contacts, difficulties with work and resumption, and impaired partner relationship hardly changed with time. In contrast, a shift in sexual problems can be noticed: nowadays, stoma patients report more frequently a loss of sexual interest. The fact that, during the last decades, the taboo has substantially been lifted from discussing sexuality and sexual problems is probably of major importance. Sexual problems mentioned in earlier studies could be more severe than reported. A remark from the report by Sutherland et al. (1952, p. 863) illustrates this possible explanation: "Women were resistant to any discussion of sexual matters: therefore, information in this area is incomplete."

Conclusion. Neither the type nor the proportion of the psychosocial problems of stoma surgery patients seems to have changed considerably between earlier studies and recent studies. Thus, recent improvements in the care for stoma surgery patients did not lead to a reduction in adaptational problems, as been hypothesized earlier. This conclusion should be interpreted with caution: Studies differ in the way in which the concept of psychosocial adaptation is defined and evaluated. We will return to this point in the methodological section of this article.

\section{Factors Contributing to Adaptation}

The variables which account for differences in adaptation between stoma patients can be considered to be social-demographic, stoma-related, illness-related, or personality-related factors (Table I).

\section{Sociodemographic Characteristics}

Only a few investigations report a link between isolated social-demographic markers and psychosocial adaptation after stoma surgery. Age and socioeconomic status do not seem to play an important role (Foulis and 


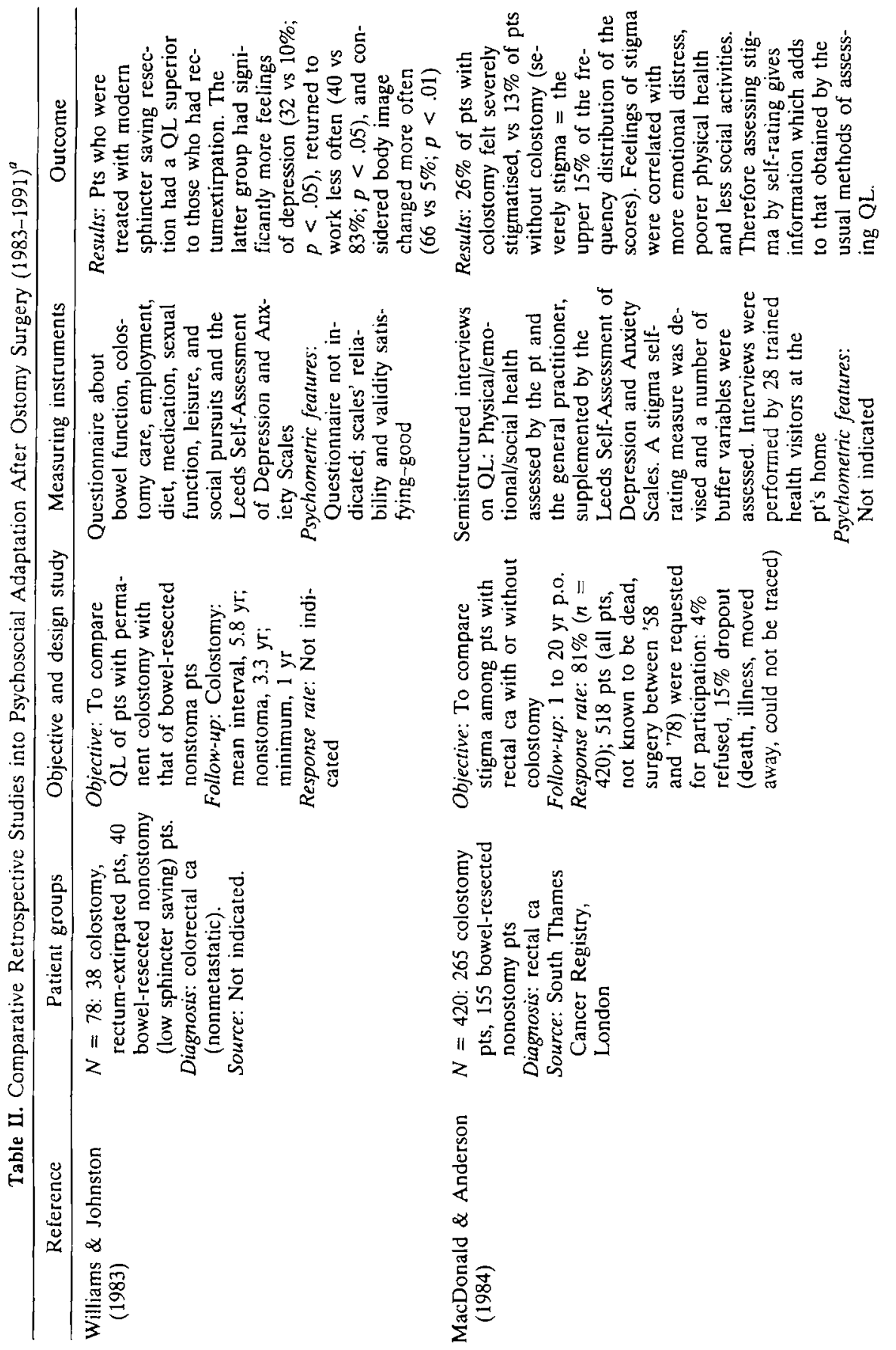




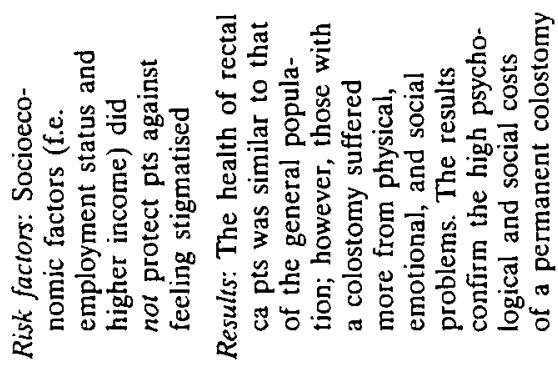

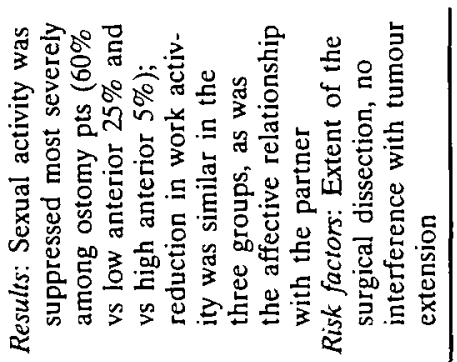
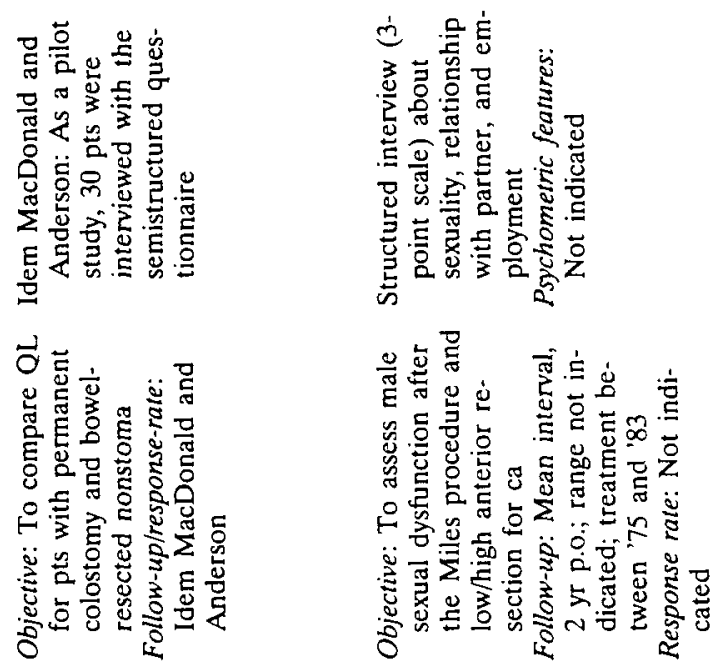

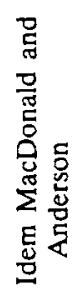

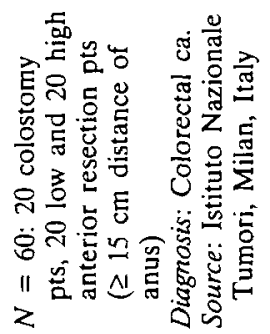

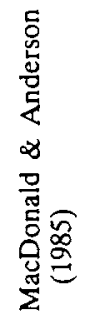

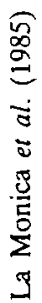




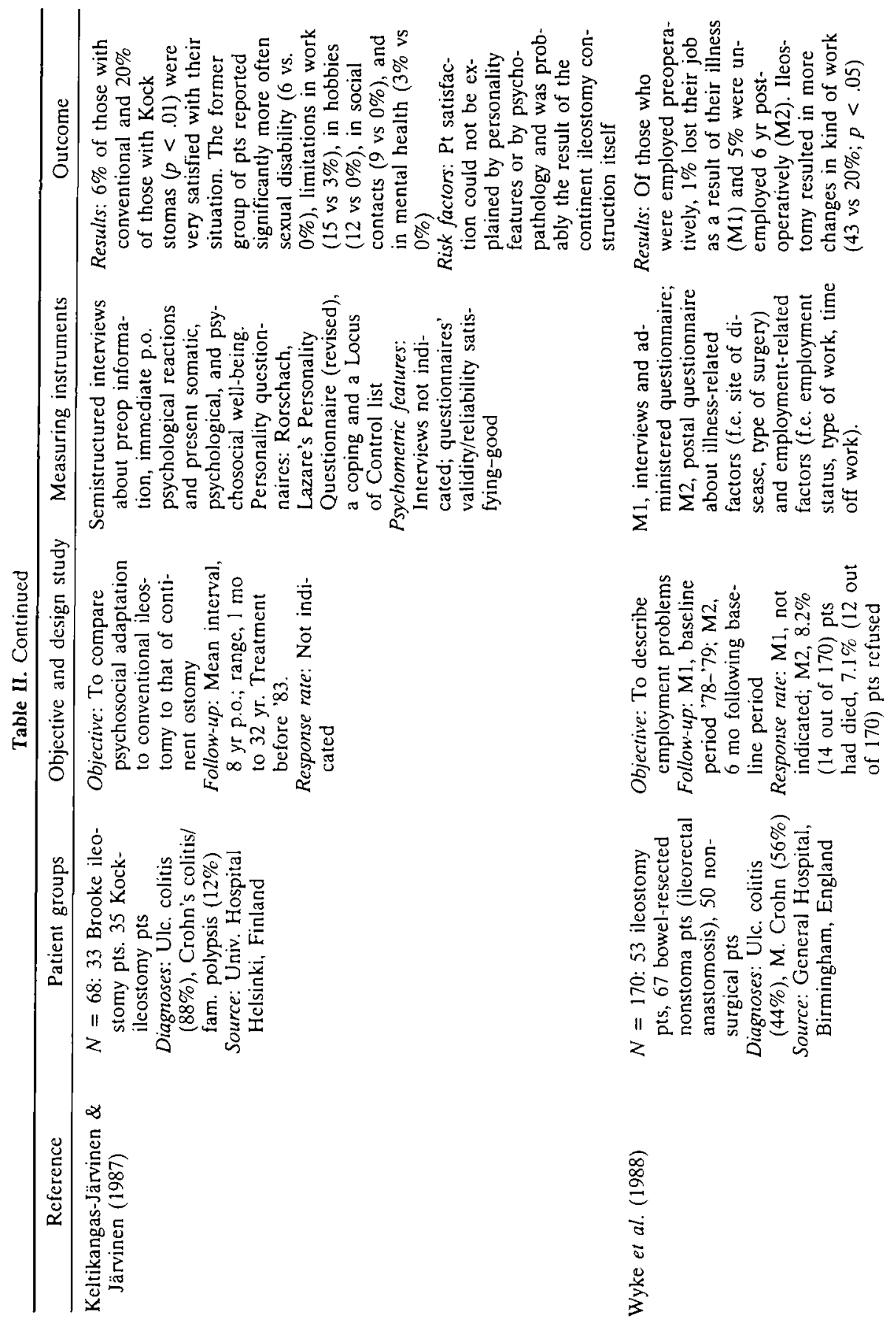




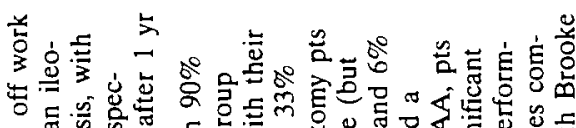

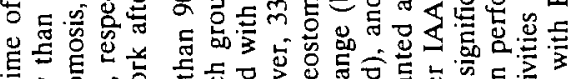

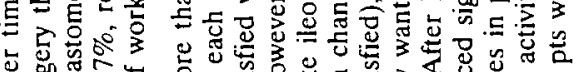

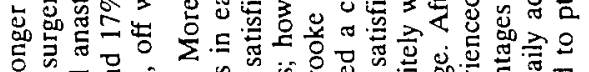

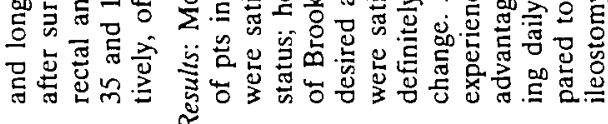

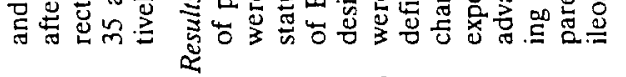

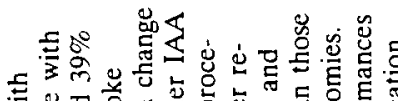

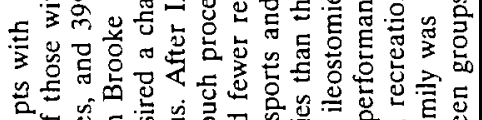

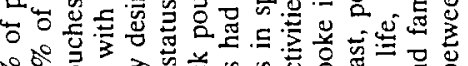

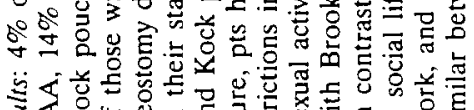

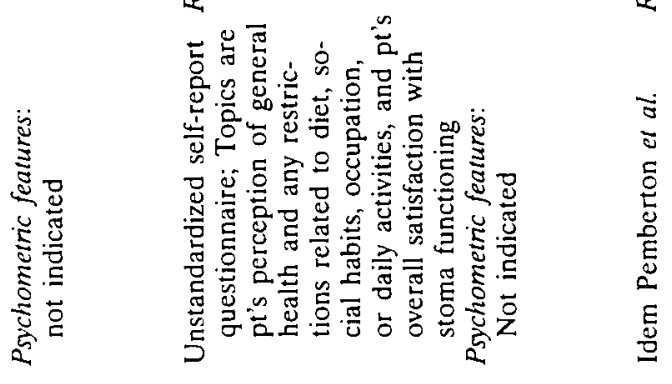

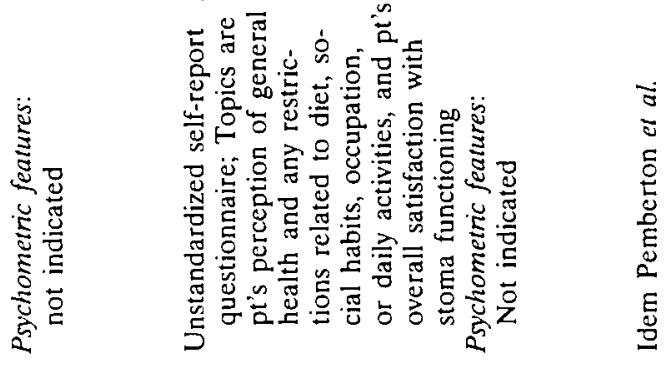

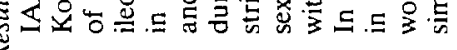

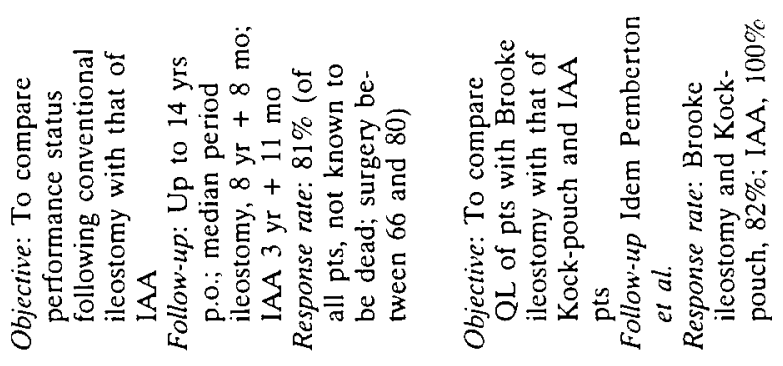

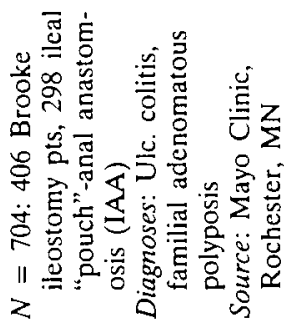

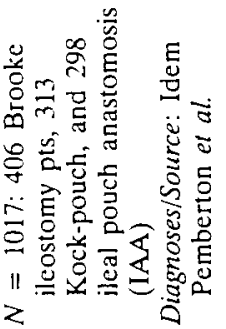

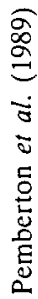

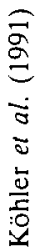




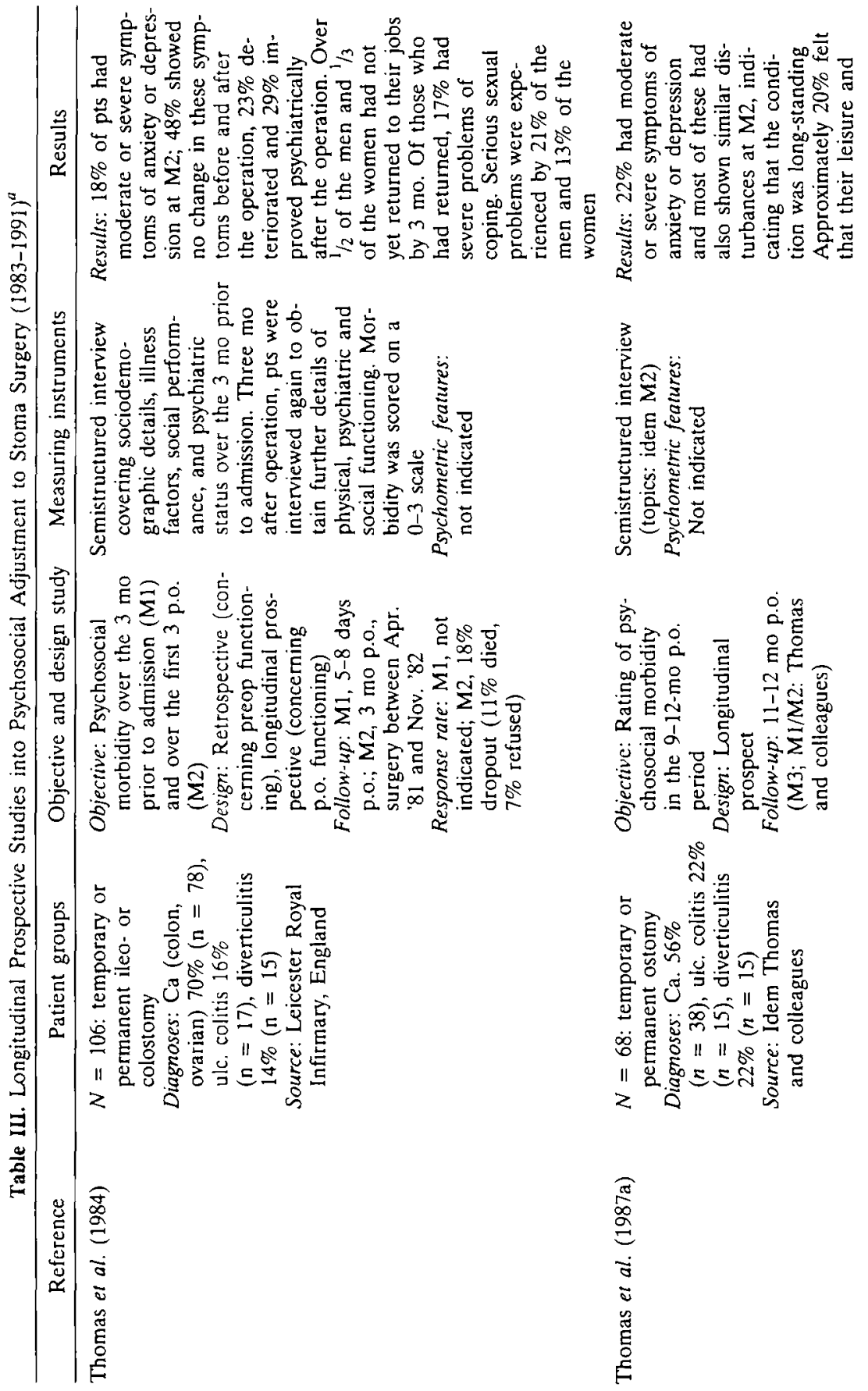



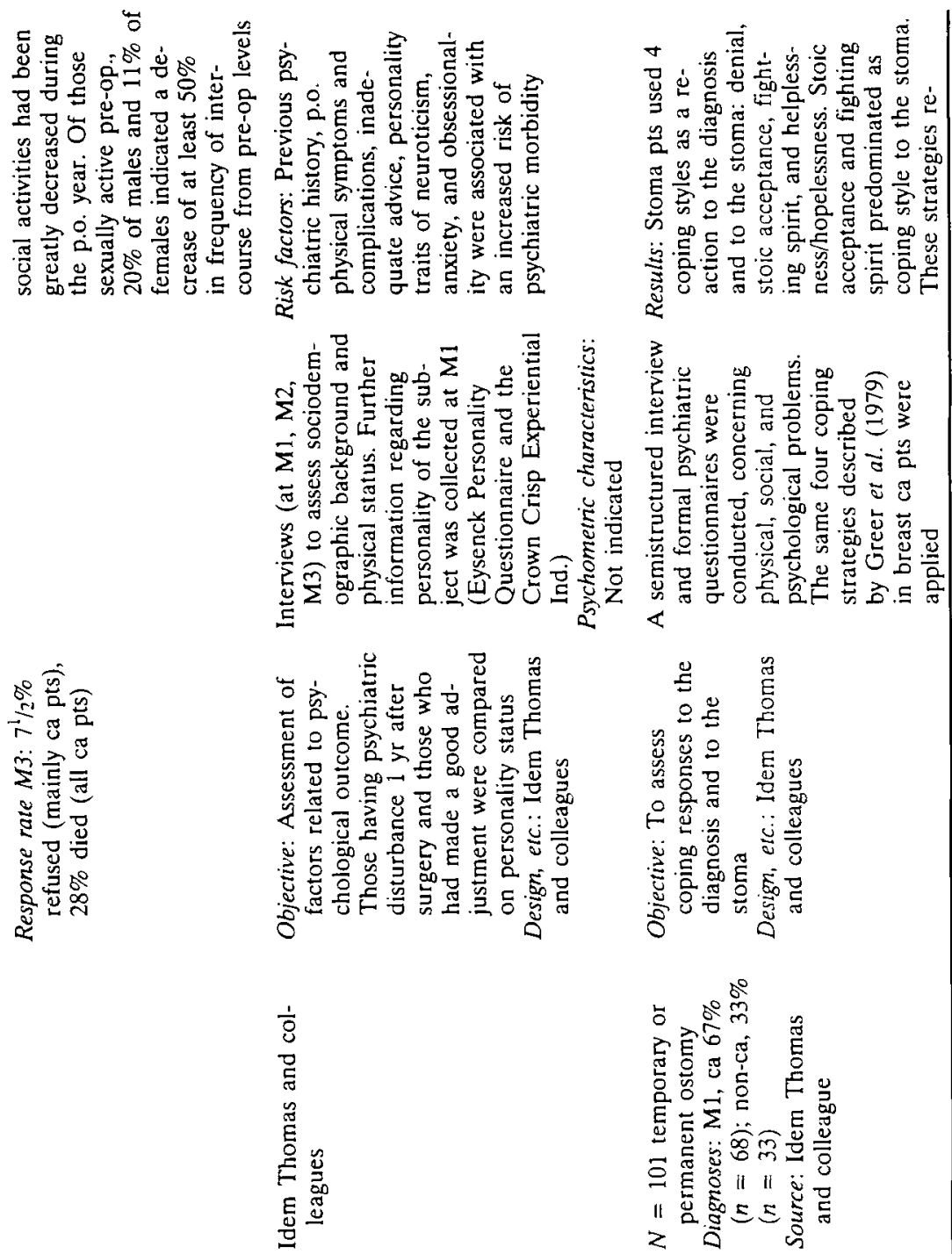

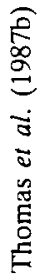

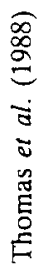




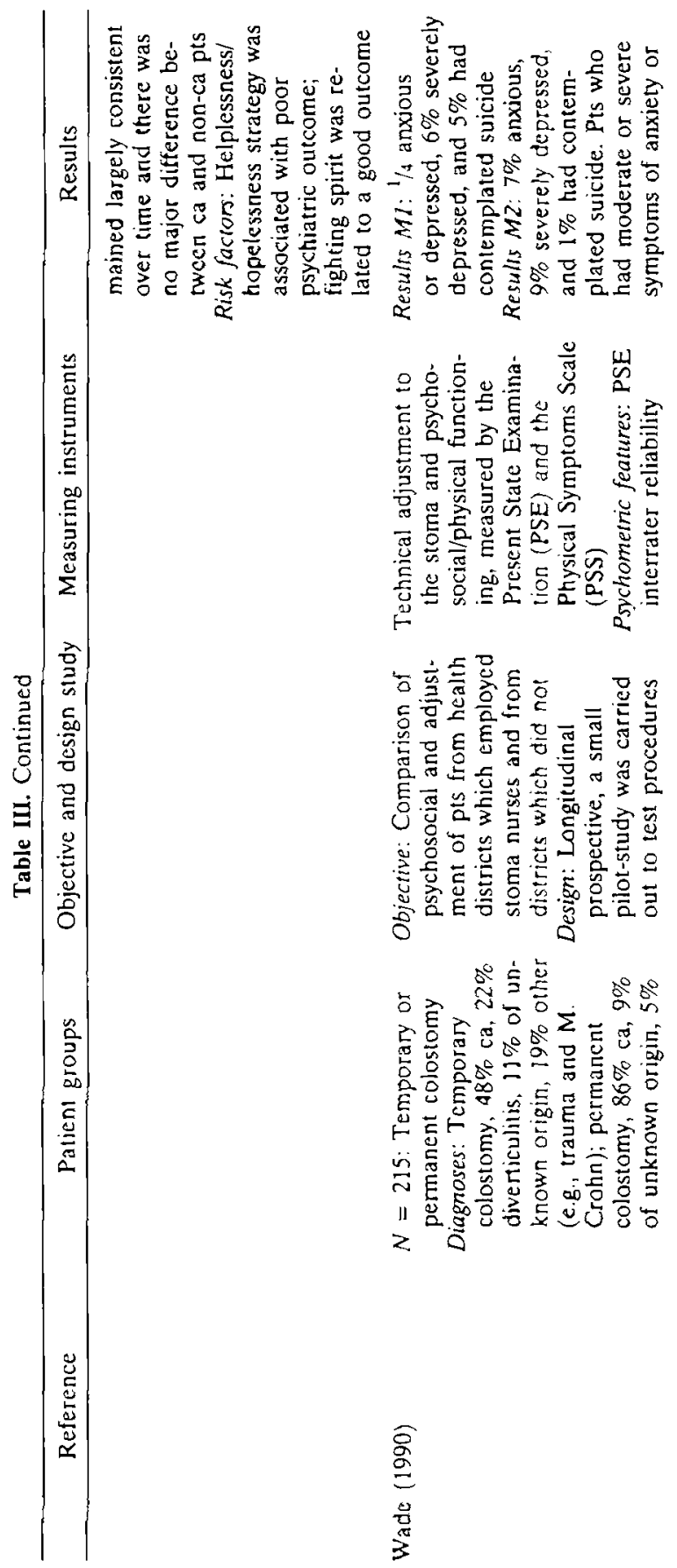




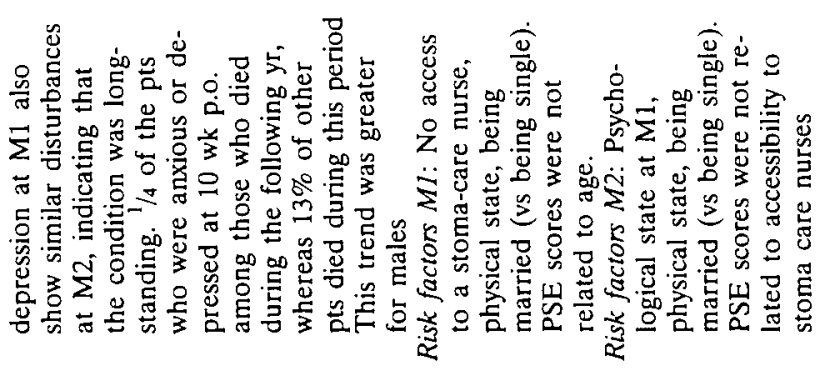

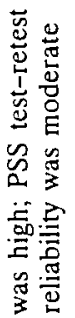

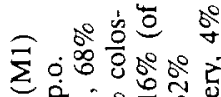

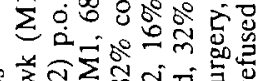

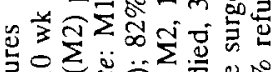

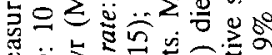

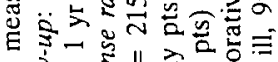

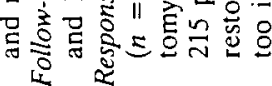

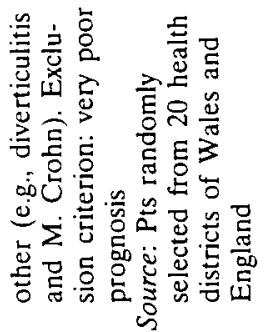




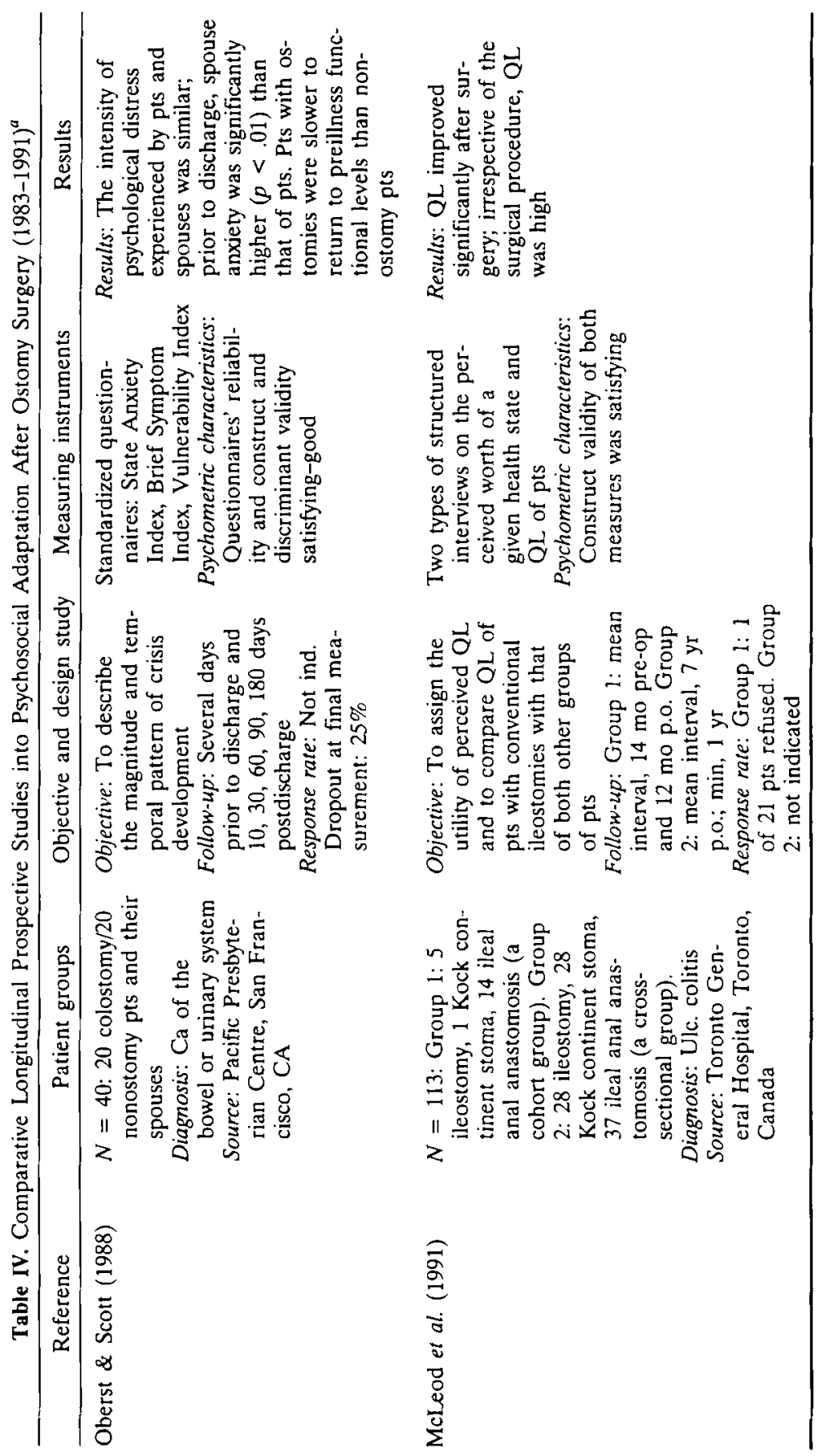




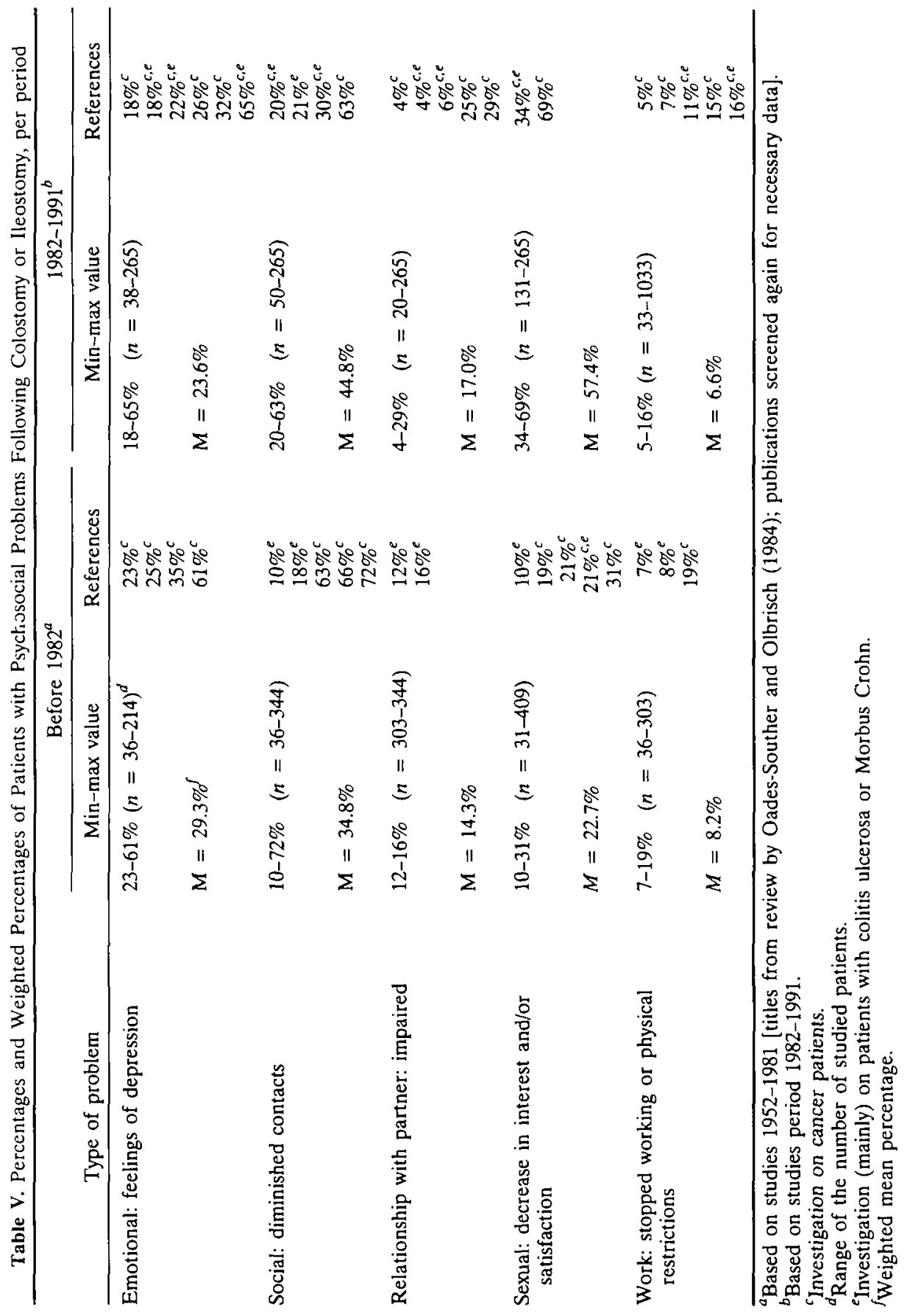


Mayberry, 1990; MacDonald and Anderson, 1984; Thomas et al., 1988; Wade, 1990).

Prior psychiatric hospitalization, marital status, and sex (Foulis and Mayberry, 1990; MacDonald and Anderson, 1984; Thomas et al., 1984, 1987a, b; Wade, 1990) seems to be associated with adjustment. Thomas et al. $(1984,1987 \mathrm{a})$ demonstrate that patients with postoperative emotional problems are found to have as many as three times more emotional problems preoperatively compared to patients with fewer postoperative problems and men have sexual problems significantly more often than women (20 versus 13\%), despite their diagnosis. van der Wiel et al. (1991) also found male colostomy patients to have more sexual problems than female patients, especially in relation to arousability, orgasmic capacity, and capability for having coitus. Ileostomy had far less drastic effects.

Wade (1990) found some evidence that single men with a stoma have a better emotional status than married male stoma patients, probably due to a loss of libido reported by many men, having a stronger negative effect on patients with a partner. These differences in emotional status usually disappear after a year.

\section{Stoma-Related Markers}

Several studies (Follick et al., 1984; Gutman and Reiss, 1985; McLeod et al., 1986; Thomas, 1987a) show that stoma-related factors have an evident predictive value regarding the process of psychosocial adaptation. These factors include a technically insufficient stoma (e.g., highly placed on body), a sensitive skin around the stoma, and insufficient skills in stoma care; the latter mark is often found in recently operated patients. In the first phase after the operation, leakage as well as skin problems is difficult to avoid, leading to all kinds of unpleasant consequences. For example, McLeod and colleagues (1986) demonstrated, in 273 conventional ileostomy patients, the quality of the stoma to be the only factor related to emotional and physical well being. Another study (Follick et al., 1984) among ileo-, colo-, and urostoma patients showed that decreased emotional $(r=-.35, p<.001)$ and social (Pearson $r=-.36, p<.001$ ) adaptation was related to the degree of leakage and skin problems. In the study by Thomas et al. (1987b), skin problems and leakage were found to be associated with less positive recovery. Finally, Gutman and Reiss (1985) indicated among a sample of Israeli colostomy patients, that patients who were instructed in flushing evacuation techniques, adjusted socially and in the working situation more easily than nonflushing stoma patients. 


\section{Illness-Related Markers}

Differences in psychosocial adaptation of stoma patients could be caused by the medical diagnosis. The differentiation between benign (e.g., Crohn's disease, ulcerative colitis) and malignant disease would seem to be of particular importance. The life-threatening character of cancer could cause an extra psychological burden. Contrary to expectation, little difference is noticed in problems experienced by patients when both types of diseases are compared (Keltikangas-Järvinen et al., 1984; Follick et al., 1984; Thomas et al., 1984, 1987a). Only with regard to psychosexual problems did stoma patients treated for cancer consistently report more problems than stoma patients treated for benign diseases (Keltikangas-Järvinen et al., 1984; van der Wiel et al., 1991). The difference could be explained by the surgical procedure. If a carcinoma is found close to the anus, the rectum stomp will be removed and a colostomy will be applied. This procedure increases the risk of injury to the autonomous nerve tracks or blood vessel in the pelvis. Such injuries may lead more often to malfunctioning of the genital organs and, consequently, to problems in (psycho)sexual adaptation.

Only the Keltikangas-Järvinen study (1989) showed less distress in cancer patients compared with noncancer patients in other areas of psychosocial adaptation. The adjustment seemed to be caused by differences in personality (see next section) and the course of the initial disease: Stoma patients with ulcerative colitis had better physical health than patients with colorectal carcinoma.

\section{Personality-Related Factors}

In general, a distinction can be made between intrapersonal (e.g., traits, attitudes) and interpersonal (e.g., social support) factors.

Little investigation has been made into the relationship between intrapersonal factors and the process of psychosocial adjustment after stoma surgery. An obsessive-compulsive personality trait (being rigid and perfectionistic), dependence (being dependent and submissive), and a poor sense of internal control (the perception of one's own influence on the course of the disease and the treatment) are investigated in a number of studies.

Thomas and colleagues (1987b) found an obsessive-compulsive personality trait to be associated with an increased risk for psychiatric morbidity shortly after surgery. In contrast, Keltikangas-Järvinen et al. (1984) suggested an obsessive-compulsive trait facilitates psychosocial adaptation. The stoma patients treated for cancer in the study by Keltikangas-Järvinen et al. (1984) had a score on dependence that was relatively high. Dependence was asso- 
ciated with relatively unfavorable adaptation. Thomas et al. (1987b), however, did not find evidence for a detrimental effect of dependence on adjustment after stoma surgery. An obsessive-compulsive personality trait cannot supposed to be a causal factor in psychosocial dysfunctioning. Some characteristics can also be interpreted as reactions to the disease (KeltikangasJärvinen, 1989). In this study, patients went through a personality investigation before they were informed about their diagnosis. Two groups were distinguished: patients mainly with ulcerative colitis and unexplained abdominal complaints and a control group consisting of patients with, for example, gallstones. The latter group has been added to control for psychological effects due to illness and medical treatment. Eighteen months after the first assessment, the psychological states were assessed again. It was found that scores on dependence and on obsessive-compulsive characteristics increased significantly as a consequence of the reaction to the diagnosis. The investigators concluded that "independent of the diagnosis, a disease increases dependence, egocentricity and suggestibility" and, consequently, that a "permanent tendency to obsessive-compulsivity has not been found" (p. 329).

There is some evidence that the expectations of stoma patients regarding the possibility to control their illness and stoma (internal control) may play a role in the adaptational process. Based on the results of a longitudinal prospective investigation (Thomas et al., 1988) among a group of coloand ileostomy patients, a feeling of being personally in control over daily functioning with a stoma, was associated with a more favourable course of the psychological adjustment.

To conclude, no systematic research has been done into interpersonal factors associated with psychosocial adjustment.

Conclusion. Stoma complications and rectum amputation as a consequence of colorectal carcinoma may be regarded as "stable" factors contributing to a less favourable course of psychosocial adaptation. The results concerning the relation between compulsive and dependent behaviour and psychosocial adaptation are rather scanty and inconsistent. Less commonly recognized is the association between (combinations of) sociodemographical factors and the nature of the medical diagnosis.

\section{Stoma vs Innovative Techniques}

Instead of stoma surgery, new surgery techniques have become available in the past few years, which can avoid the introduction of a regular stoma. One of these innovative techniques, is the so-called ileonal anastomosis with pouch construction (IAA) (see Glossary). In some cases, it is also possible to make a continent stoma (ileal pouch according to Kock) (see Glossary) 
instead of the regular stoma. A colostomy can be avoided more often by the so-called "low-anterior resection" (see Glossary) for a rectum carcinoma.

There are a few studies which compare adjustment after stoma surgery with these recent techniques, demonstrating that every type of bowel surgery induces a certain degree of postoperative psychosocial disability to the patient. New techniques seem to have a relatively favourable effect. Investigation (Köhler et al., 1991) among patients with ulcerative colitis and polyposis coli shows that the IAA-patients and the patients with a continent stoma less often desire a change in their present physical situation than ileostomy patients: 4,14 , and $39 \%$, respectively. Another study (Keltikangas-Järvinen and Järvinen, 1987) shows that patients with a continent stoma were more satisfied than the conventional ileostomy patients (20 vs 6\%; $p<.01)$. McLeod et al. (1991) found no difference in the quality of life between ulcerative colitis patients with a conventional stoma, an ileoanal anastomosis or a continent stoma. A relatively high quality of life was reported by all patients.

According to Williams and Johnston (1983), Is the quality of life of cancer patients who underwent a "low anterior resection" superior to that of colostomy patients? Stoma patients scored higher scores on depression (32 vs $10 \% ; p<.05$ ), more often reported a change in their body image ( 66 vs $5 \% ; p<.01$ ), and returned to their job after surgery less frequently (40 vs $83 \% ; p<.05$ ). The conclusions of MacDonald and Anderson (1984, 1985) are consistent with these findings. These authors estimated the psychological, social, and physical "costs" of patients treated for colorectal carcinoma. Stoma patients showed substantially more complaints of depression and experienced more physical and sexual impairments than nonstoma bowel-resected patients. Twice as many colostomy patients (26\%) as resection patients (13\%) felt stigmatized to a serious extent.

Conclusion. Patients who are treated with new surgery techniques, such as IAA and continent stoma, seem to report fewer psychosocial problems. The number of investigations, however, is still small and retrospective. This does not warrant a correct estimation of the level of psychosocial problems, because no correction for biasing influences is made, such as response shift (see also Design, under Methodological Evaluation). Only longitudinal investigations can give a complete and undistorted picture of the course of psychosocial suffering.

\section{Methodological Evaluation}

We analyzed the methodological characteristics of the studies on stoma patients published in the last decade by taking a closer look at the com- 
position of the patient groups, the research designs, and the selection of instruments.

\section{Patient Groups}

To draw valid conclusions about the well-being of stoma patients, studies must be based on representative samples from the whole population of stoma patients. In general, the samples in the reviewed studies stem from two different populations: from the medical records of a hospital (often academic) or from organizations of stoma or cancer patients. In both cases, the actual population can be biased in one or more ways.

Response rate of the patients which were potentially considered for participation in the project varied from 33\% (Follick et al., 1984) to more than 90\% (Foulis and Mayberry, 1990). In the retrospective studies (three of four) some other factors, apart from refusal, played a role that accounted for the dropout of some specific groups of patients. First, dropout may be based on death between surgery and selection (e.g., as a result of a relapse of intestinal cancer) before a retrospective study has started up. Dropout of this type can be extensive, as is shown in some longitudinal, prospective studies: Percentages may vary from $16 \%$ (Wade, 1990) to $28 \%$ (Thomas, 1987a) within a year after surgery. Interesting, in this respect, were the results of a study by Wade (1990) on the immediate postoperative adaptation to stoma surgery. She found dropout based on death to be associated with depression: Considerably more depressive than nondepressive patients dropped out of the study ( 25 vs $13 \%$ ). Finally, dropout may occur because patients chose one of the newly available innovative surgery techniques and had their stoma removed. No exact data on this subject could be found in the literature.

All the factors mentioned have a positive biasing effect on the outcome of the investigations: Some of the "less strong" dropped out before the actual investigation took place. The results of retrospective studies are therefore only moderately representative of the stoma population.

\section{Design}

Two studies are based on a fully prospective, longitudinal research design (Wade, 1990; Oberst and Scott, 1988), two other studies combined a prospective longitudinal research design with a retrospective one (Thomas et al., 1984, 1987a, b, 1988), and all the other studies had a retrospective design. Some important difficulties are inherent to both the prospective as well as the retrospective studies. 
The first drawback concerns the lack of a control group of patients in over half of the investigations. Every type of surgery causes a certain extent of psychological distress. There is no relationship between the level of psychological distress in the first 3 months after surgery and the type of surgery (O'Hara et al., 1989). Patients undergoing cardiovascular surgery, intestinal surgery, cholecystectomy, or hysterectomy, all had a comparable scoring pattern on the Brief Symptom Inventory. In each group, about $14 \%$ showed a large degree of psychological distress. No difference could be noticed between patients who had disfiguring surgery as a consequence of carcinoma (for instance mastectomy) and patients who were treated for nonmalignant disorders without disfiguring effects.

These results are also relevant for research among stoma patients. Without a control group, it is impossible to separate the general reactions of distress to the disease and the treatment from the specific consequences of stoma surgery. Especially in a longitudinal design, it is necessary to make a comparison with other patients who have recently been operated, because it is in this phase that patients suffer most of the psychological distress. Two of the four longitudinal studies (Thomas, 1984; Wade, 1990) lacked such a control group. One of the two other longitudinal studies (Oberst and Scott, 1988) included a control group in the design, but this group had a modest number of subjects $(N=20)$ and consisted of patients with varying types of cancer. In the McLeod et al. study (1991), only 5 stoma patients participated, while the control group consisted of 15 respondents.

The second drawback concerns inappropriate design to meet the purpose of investigation. Half of the retrospective studies wcre totally or partially set up to describe the process of psychosocial adjustment after stoma surgery. A retrospective design, however, is only partly suitable to describe that process. In the first place, this related to the selective memory of people. There was an average time of 5.8 years (Williams and Johnston, 1983 ) to 15 years (Foulis and Mayberry, 1990) between stoma surgery and the retrospective investigations, with a range from several months to often more than 20 years. The patient is often not able to reproduce the type or extent of the psychosocial problems after such a long period. Secondly, the occurrence of response shift influences reporting: people tend to judge their feelings and experiences of past and present according to currently prevailing standards (Sprangers, 1988). In the case of stoma surgery, the patient will tend to describe the postoperative recovery period more favourable retrospectively than in fact was the case, in order to justify stoma surgery. Before the operation, being socially and economically active is most important; after the operation, being grateful for living is the predominant feeling. 
In summary, retrospective stoma investigation offers an incomplete and distorted picture of reality and does not describe the process of psychosocial adaptation adequately. It can give only a random indication of the adjustment to the stoma in the long-term.

\section{Measuring Instruments}

In almost every study a different meaning is given to "psychosocial adaptation" or "quality of life." This makes an objective comparison of the results somewhat difficult. Most of the studies used self-reporting questionnaires as a primary method for collecting data. These questionnaires have not been standardized, with the exception of the personality questionnaires in the Keltikangas-Järvinen studies $(1984,1987)$. Furthermore, no psychometric qualities concerning validity or reliability of the used scales were provided in any study.

Conclusion. Some methodological improvements can be seen since the conclusions of Oades-Souther and Olbrisch (1984). Longitudinal research has been conducted, and in general, the character of the disease under study is taken into consideration. However, due to the lack of control groups, it remains unclear to what extent stoma surgery, or other factors, accounts for the observed problems. In addition, most studies fail to give a psychometric description of the measuring instrument.

\section{DISCUSSION}

After stoma surgery, patients report considerable psychosocial problems, as evidenced by this review. A comparison of the most recent and earlier literature with respect to psychosocial problems seems to indicate that the types and the extent of problems did not change. This conclusion is confirmed by the results from the Pemberton investigation (1989) among patients with an ileostomy. They found that the clinical and the functional results of these patients were not substantially different from those of patients with an ileostomy treated 20 years before. It was, furthermore, indicated that the incidences of postoperative complications did not change. In general, recent improvements in stoma care seems not to have led to a decline in the psychosocial problems. Objective research can make a major contribution to the improvement of psychosocial care of stoma patients. Apparently, investigation offers still insufficient leads for specific psychological interventions aimed at an improvement in the well-being of stoma patients. 
Conclusions of the research thus far should be interpreted with caution. Despite the methodological improvements (a rising number of longitudinal studies, the character of the disease is taken into account) in many studies during the last few years, some important drawbacks (lack of control groups, no psychometric data) can be noticed. The extended range in incidence of psychosocial problems occurring in areas of adaptation which are conceptually closely related is probably due mainly to defective measuring instruments and operationalizations. Further development of instruments and a more unequivocal definition of psychosocial adaptation may improve the comparability between results of various investigations.

There is a need for more longitudinal research with adequate control groups. Control groups should consist of surgical patients without a stoma (high or low anterior resection, small intestinal resection for inflammatory diseases, IAA). More attention should be paid to the specific character (cancer vs noncancer) of the disease in order to find out the influence of the type of disease on the process of adaptation after stoma surgery. Only then will more insight be obtained into the course of the adaptational process and what time stoma patients need to adapt to their new situation. Only then can the relative role of the stoma be determined, and it will be possible to sort out the causes of specific adaptational problems.

Special attention should be paid to the role of sociodemographic characteristics and medical and psychological factors which could offer an explanation for differences in adaptation between patients. In this way, patient groups at risk to develop problems in the adaptational process at an early stage can be tracked, thus enabling guided extra attention to these patients.

A subgroup of patients with intestinal disease are, in certain circumstances, eligible for an alternative surgical procedure which avoids the application of a stoma, such as IAA, in the case of ulcerative colitis or polyposis coli, or low anterior resection, in the case of colorectal cancer. At the moment, we are at the start of the discussion about the desirability of these procedures compared to conventional stoma surgery.

Psychosocial investigation can offer an important contribution to this discussion by clarifying the psychological consequences of these different surgical techniques for the patients. The first results indicate a favourable trend toward IAA and low anterior resection. However, due to lack of investigations with sophisticated designs, it is difficult to assess the advantages of the new techniques in psychological terms. Longitudinal investigations provide more objective results. As we have pointed out, patients tend to justify the choices they made in the past which, in turn, may lead to an underestimation of the psychosocial consequences in retrospective studies. This effect may be reinforced by the process of selectivity: often it concerns 
patients who choose alternative surgery because they were not satisfied with the conventional stoma. Furthermore, serious postoperative complications may occur, such as an internal leak or pouchitis; the patient may suffer a very high frequency of bowel movement (e.g., Slors et al., 1990; Skarsgard et al., 1989). After the construction of a continent stoma necrosis or dysfunctioning of the valve mechanism, fistula formation and intestinal obstruction are reported as frequent complications (Köhler et al., 1991; Sjödahl et al., 1990). Further development of surgical alternatives for a stoma seems imperative since there seems to be no reduction in the psychological and functional problems after conventional stoma surgery thus far. It is obvious that medical and psychological evaluation should run parallel with these developments.

To conclude, studies should be carried out in explicit theoretical framework. Such a framework could offer more specific clues into the psychosocial adaptation after stoma surgery, which includes a better understanding of the course of the adaptational process.

\section{GLOSSARY}

Colon. The large intestine.

Crohn's disease (M. Crohn). Chronic inflammatory bowel disease, especially localized in the terminal ileum (last part of the small intestine), the large intestine, or both. The disease affects the whole thickness of the bowel wall and extends often diffusely through the length of the colon and/or terminal ileum; in other cases a more segmental pattern is seen. There are frequently ulcers in the intestinal mucosa and fistulas between the bowel and, for example, the urinary or genital tract, the skin, or the area beside the anus. In the course of the disease in most cases several operations are needed.

Ulcerative colitis (or idiopathic proctocolitis). Chronic inflammatory bowel disease, affecting the mucosal layer only. The disease can, mostly from the anus upward, reach any part of the large intestine, up to the whole of the colon. There are several degrees of seriousness; exacerbations are common.

Polyposis coli. A hereditary disease with many ( $>100$ or many hundreds of) polyps in the large intestine. These are so-called adenomatous polyps, benign neoplasms, but with a great tendency towards malignancy. Because of the very great number of polyps, cancer will invariably develop. Therefore the colon must be removed prior to this malignant change.

Colectomy. Surgical removal of the large intestine. Total proctocolectomy: The whole of the colon is removed, including the rectum, and a 
permanent ileostoma is made. If the anus can be saved, in some cases, an ileoanal anastomosis can be constructed. Subtotal colectomy: Rectum and anus remain in situ. In some cases an ileorectal anastomosis can be made. In other cases, a permanent or temporary ileostoma is needed, depending on the nature of the disease.

Ileoanal ("pouch") anastomosis. After removal of the whole of the large intestine (in one or two operations), a pouch is constructed out of the last part of the small intestine and is connected to the anus.

Continent Stoma. In a somewhat different way from the one mentioned above, a pouch is constructed out of the last part of the small intestine with a kind of valve mechanism. The end of the valve is stitched into the skin, at the same place where the ileostoma would otherwise have been placed. In contrast to the conventional stoma a continent stoma is not or hardly visible from the outside, and an appliance is not necessary. The patient has to empty the pouch, with a tube, several times a day.

Resection. The removal of a diseased part of the bowel. An anastomosis can be made with the two ends.

Low anterior resection. In cases of cancer of the rectum the surgeon can, in contrast to earlier days, construct a very low anastomosis, up to only a few centimeters above the anus. In this way a colostomy can be prevented.

Enema. Rinse of the bowel through the stoma opening. A number of patients with a colostomy give themselves a daily enema with a specially made system. In this way the feces is removed once a day, and only a small appliance is necessary or, in some cases, no appliance at all.

\section{REFERENCES}

Burnham, W. R., Lennard-Jones, J. E., and Brooke, B. N. (1977). Sexual problems among married ileostomists. Gut 18: 673-677.

Devlin, H. B., Plant, J. A., and Griffin, M. (1971). Aftermath of surgery for anorectal cancer. BMJ 3: 413-418.

Dlin, B. M., Perlman, A., and Ringold, E. (1969). Psychosexual response to ileostomy and colostomy. Am. J. Psychiatry 126: 374-381.

Druss, R. G., O'Connor, J. F., Prudden, J. F., and Stern, L. O. (1968). Psychological response to colectomy. Arch. Gen. Psychiatry 18: 53-59.

Druss, R. G., O'Connor, J. F., and Stern, L. O. (1969). Psychological response to colectomy. II. Adjustment to permanent colostomy. Arch. Gen. Psychiatry 20: 419-427.

Dukes, C. E. (1947). Management of permanent colostomy. Lancet 2: 12-14.

Dyk, R. B., and Sutherland, A. M. (1956). Adaptation of the spouse and other family members to the colostomy patient. Cancer 9: 123-138.

Eyskens, E., Feenstra, L., Meinders, A. E., and Vandenbroucke, J. P. (1991). Codex Medicus, Elsevier Koninklijke PNBA, pp. 245-246.

Follick, M. J., Smith, T. W., and Turk, D. C. (1984). Psychosocial adjustment following ostomy. Health Psychol. 3: 505-517. 
Foulis, W. F., and Mayberry, J. F. (1990). Elderly ileostomists and their social problems. J. Clin. Gastroenterol. 12, 276-278.

Gutman, H., and Reiss, R. (1985). Postoperative course and rehabilitation achievements of colostomates. Dis. Colon Rectum 28: 777-781.

Hengeveld, M. W. (1987). Stoma en seks: sexuele problemen na proctocolectomie of rectum-extirpatie. Ned. Tijdschr. Geneeskd. 131: 1254-1255.

Keltikangas-Järvinen, L. (1989). "Psychosomatic personality"-A personality constellation or an illness-related reaction? Br. J. Med. Psychol. 62: 325-331.

Keltikangas-Järvinen, L., and Järvinen, H. J. (1987). Psychosocial adaptation to ileostomy: A study after construction of conventional and continent stomies. Scand. J. Gastroenterol. 22: 202-206.

Keltikangas-Järvinen, L., Loven, E., and Möller, C. (1984). Psychic factors determining the long-term adaptation of colostomy and ileostomy patients. Psychother. Psychosom. 41: 153-159.

Köhler, L. W., Pemberton, J. H., Zinsmeister, A. R., and Kelly, K. A. (1991). Quality of life after proctocolectomy. A comparison of Brooke ileostomy, Kock-pouch and ileal pouch-anal anastomosis. Gastroenterology 101: 679-684.

La Monica, G., Audisio, R. A., Tamburine, M., Filberti, A., and Ventafridda, V. (1985). Incidence of sexual dysfunction in male patients treated surgically for rectal malignancy. Dis. Colon Rectum 28: 937-940.

MacDonald, L. D., and Anderson, H. R. (1984). Stigma in patients with rectal cancer: a community study. J. Epidemiol. Commun. Health 38: 284-290.

MacDonald, L. D., and Anderson, H. R. (1985). The health of rectal cancer patients in the community. Eur. J. Surg. Oncol. 11: 235-241.

McLeod, R. S., Lavery, I. C., Leatherman, J. R., Maryland, P. A., Fazio, V. W., Jagelman, D. G., and Weakley, F. L. (1986). Factors affecting quality of life with a conventional ileostomy. World J. Surg. 10: 474-480.

McLeod, R. S., Churchill, D. N., Lock, A. M., Vanderburgh, S., and Cohen, Z. (1991). Quality of life of patients with ulcerative colitis preoperatively and postoperatively. Gastroenterology 101: 1307-1313.

Oades-Souther, D., and Olbrisch, M. E. (1984). Psychological adjustment to ostomy surgery Rehab. Psychol. 29: 221-237.

Oberst, M. T., and Scott, D. W. (1988). Postdischarge distress in surgically treated cancer patients and their spouses. Res. Nurs. Health 11: 223-233.

O'Hara, M. W., Ghoneim, M. M., Hinrichs, J. V., Mehta, M. P., and Wright, E. J. (1989). Psychological consequences of surgery. Psychosom. Med. 51: 356-370.

Pemberton, J. H., Phillips, S. F., Ready, R. R., Zinsmeister, A. R., and Beahrs, O. H. (1989). Quality of life after Brooke ileostomy and ileal pouch-anal anastomosis. Ann. Surg. 209: 620-626.

Roy, P. H., Sauer, W. G., Beahrs, O. H., and Farrow, G. M. (1970). Experience with ileostomies: Evaluation of long-term rehabilitation in 497 patients. Am. J. Surg. 119: 77-86.

Sjödahl, R., Lemon, E., Nyström, P., and Oleison, G. (1990). Complications, surgical revision and quality of life with conventional and continent ileostomy. Acta Chir. Scand. 156: 403-407.

Skarsgard, E. D., Atkinson, K. G., Bell, G. A., Pezim, M. E., Seal, A. M., and Sharp, F. R. (1989). Function and quality of life results for chronic ulcerative colitis and familial polyposis. Am. J. Surg. 157: 467-471.

Slors, J. F. M., Taat, C. W., and Brummelkamp, W. H. (1990). De ileo-anale anastomose met ileum-reservoir. Ned. Tijdschr. Geneeskd. 1334, 134: 337.

Sprangers, M. A. G. (1988). Response Shift and the Retrospective Test: On the Usefulness of Retrospective Pretest-Posttest Designs in Detecting Training Related Response Shifts, Instituut voor Onderzoek van het Onderwijs, SVO, 's-Gravenhage.

Sutherland, A. M., Orbach, C. E., Dyk, R. B., and Bard, M. (1952). The psychological impact of cancer and cancer surgery. I. Adaptation to dry colostomy; preliminary report and summary of findings. Cancer 5: 857-872. 
Thomas, C., Madden, F., and Jehu, D. (1984). Psychosocial morbidity in the first three months following stoma surgery. J. Psychosom. Res. 28: 251-257.

Thomas, C., Madden, F., and Jehu, D. (1987a). Psychological effects of stomas. I. Psychosocial morbidity one year after surgery. J. Psychosom. Res. 31: 311-316.

Thomas, C., Madden, F., and Jehu, D. (1987b). Psychological effects of stomas. II. Factors influencing outcome. J. Psychosom. Res. 31: 317-322.

Thomas, C., Turner, P., and Madden, F. (1988). Coping and outcome of stoma-surgery. $J$. Psychosom. Res. 32: 457-467.

United Ostomy Association (1985). Annual Report.

van der Wiel, H. B. M., Weijmar Schultz, W. C. M., Hengeveld, M. W., and Staneke, A. (1991). Sexual functioning after ostomy surgery. Sex. Mar. Ther. 6: 195-209.

Wade, B. E. (1990). Colostomy patients: Psychological adjustment at 10 weeks and 1 year after surgery in districts which employed stoma-care nurses and districts which did not. J. Adv. Nurs. 15: 1297-1304.

Watts, J. M., de Dombal, F. T., and Goligher, J. C. (1966). Long-term complications and prognosis following major surgery for ulcerative colitis. Br. J. Surg. 53: 1014-1023.

Whates, P. D., and Irving, M. (1984). Return to work following ileostomy. Br. J. Surg. 71: 619-622.

Williams, N. S., and Johnston, D. (1983). The quality of life after rectal excision for low rectal cancer. Br. J. Surg. 70: 460-462.

Wirsching, M., Drüner, H. U., and Herrmann, G. (1975). Results of psychosocial adjustment to long-term colostomy. Psychother. 26: 245-256.

Wyke, R. J., Edwards, F. C., and Allan, R. N. (1988). Employment problems and prospects for patients with inflammatory bowel disease. Gut 29: 1229-1235. 